\title{
O PARADIGMA AMBIENTAL E A QUESTÃO AGRÁRIA A PARTIR DO ESTUDO DOS AUTOS DE INFRAÇÃO AMBIENTAL DO IBAMA NO ESTADO DO RIO DE JANEIRO
}

\author{
Ana Claudia Diogo Tavares e Erika Macedo Moreira. \\ Mestrandas no Programa de Pós-Graduação em Sociologia e Direito da Universidade Federal \\ Fluminense - PPGSD/ UFF \\ e-mail: anaclaudiatavares@yahoo.com e erika_adv@ig.com.br
}

RESUMO: No presente trabalho refletimos sobre a função social como elemento fundamental do conceito de propriedade. Mediante uma análise dos autos de infração aplicados pelo Ibama, em áreas adjacentes à Reserva Biológica de Poço das Antas, discutimos como (ou se) os princípios ambientais incorporam políticas agrárias. Partimos do pressuposto de que as ciências da terra - agrária e ambiental - devem caminhar de forma harmônica, pois são interdependentes. Classificamos e analisamos a legislação, os tipos penais mais freqüentes, as áreas de maior incidência, a atuação dos agentes fiscalizadores e seus critérios na atribuição dos valores a título de multa pela infração.

PALAVRAS-CHAVE: Direitos socioambientais; Justiça ambiental; Reforma Agrária; Questão ambiental. 


\section{INTRODUÇÃO}

A escolha desta temática está ligada à confecção, no correr de 2001, de laudo multidisciplinar sobre conflito socioambiental na região ${ }^{1}$, quando, no curso do processo de pesquisa-ação, nossa equipe procurou aprofundar a discussão sobre a efetividade dos autos de infração na tutela ambiental; em especial, em face da curiosidade despertada nas falas de trabalhadores(as) rurais da região, quando questionavam o tratamento diferenciado dado pelo órgão fiscalizador no momento das autuações. Segundo eles, "quando trabalhador rural pisa, é Mata Atlântica; quando fazendeiro pisa, é mato". Buscamos verificar se a hipótese de perseguição alegada conferia com o número de autuações ambientais efetuadas pelos agentes do Ibama.

Buscamos, nos argumentos levantados nos autos de infração, o discurso predominante, para analisar a forma como representantes do órgão responsável pelas políticas ambientais entendem a questão, e se consideram, ou não, a questão agrária e social nas suas ações.

A crise ambiental, propagada por movimentos ecologistas, reflete um problema de origem social e econômica que traz conseqüências no âmbito ambiental. Clóvis Ultramari², apresenta uma síntese de cinco eixos do discurso ambiental - demonstrando como este vem sendo apropriado, não para o manejo das fontes naturais, mas para a sua adequação a interesses econômicos específicos, transfigurado numa visão mercadológica, que transforma fontes em recursos naturais. Atualmente, refletir a problemática ambiental é, sobretudo, reconhecer práticas diferenciadas entre homem/natureza. A Reforma Agrária pode se constituir em importante instrumento de defesa do meio ambiente, uma vez que traz ênfase no modelo da agricultura familiar, que acarreta práticas não impactantes, tanto ao meio social onde se desenvolvem os projetos de assentamento como no meio ambiente. Embora possa ser também um instrumento predatório ao ambiente, no caso da

1 MADEIRA FILHO, Wilson et al. Laudo multidisciplinar e termo de cooperação técnica para a convivência harmoniosa de assentamentos rurais no entorno da Reserva Biológica de Poço das Antas. Niterói: UFF, 2002. (CD Room). Também disponível em www.crea-rj.org.br_, acesso em 20 abr. 2005. 
reprodução de um modelo econômico intensamente dependente da utilização de agrotóxicos e insumos químicos, o que se verifica na política agrária implementada pelo Incra.

Para muitos jusagraristas, não há que se falar em propriedade se a sua função social não é cumprida. Portanto, ela representa elemento constitutivo da propriedade, não devendo ser paga indenização a quem não a cumpre, pois representaria enriquecimento sem causa.

A questão ambiental traz para a questão agrária nova compreensão à propriedade privada, impondo-Ihe a necessidade de considerar a adequada utilização da terra, para alcançar sua função social. Para Carlos Frederico Mares, "o vasto espectro da questão ambiental, sempre coletivo e exatamente por isso novo para um direito fundado no princípio individual, agrega-se ao Direito Agrário, modifica-o, atualiza-o, torna-o mais claramente emancipatório". ${ }^{3}$

A partir da análise dos dados levantados, refletiremos acerca da possibilidade dos critérios ambientais serem incorporados no cálculo da produtividade para a desapropriação de áreas com fins de reforma agrária, sem que se esvazie o próprio conceito da função social. Assim, buscamos uma teoria que rompa com o víeis economicista do conceito de produtividade.

\section{METODOLOGIA}

Inicialmente, realizamos um levantamento bibliográfico, a fim de conhecer as diversas leituras sobre a questão ambiental e compreender as legislações vigentes à época das infrações. ${ }^{4}$

O trabalho de campo foi fundamentalmente realizado na Superintendência do Ibama do Rio de Janeiro, que, diante de ofício encaminhado pela universidade, autorizou a vista dos processos referentes aos autos de infração da área no marco

2 ULTRAMARI, C. Das falácias naturalistas. Disponível em: http://www.unilivre.org.br/centro/textos/ forum/falacias. Acesso em 20 de abril de 2004.

${ }^{3}$ MARES, Carlos Frederico. A função social da terra. Porto Alegre: Sergio Antonio Fabris Editor, 2003, p.50.

${ }^{4}$ Verificamos a incidências das seguintes normas e regulamentos: Lei $4.771 / 65$, que institui o novo Código Florestal; Lei 5.197/67, que dispõe sobre a proteção à Fauna; Lei 6.938/81, que dispõe sobre a Política Nacional do Meio Ambiente (PNMA); Lei 7.679/88 Dispõe sobre a proibição da pesca de espécies em períodos de reprodução; Portarias 120/92, 44/93-N, 227/95(MMA), 89/96, 90/96, 92/96, 039/88-P, 267/88-P, 94/98-N 
temporal dos últimos dez anos, fornecendo total apoio à pesquisa, sem o qual esta não teria sido possível. ${ }^{5}$

Diante da autorização, a Divisão de Fiscalização (Dicof) selecionou e apresentou listagens com um total de 148 autos de infração, dos quais 125 foram analisados; ${ }^{6}$ indicando os setores onde cada um dos processos se encontrava. A partir de então, percorremos cada setor, promovendo um dessecamento dos processos, analisando cada etapa do procedimento administrativo. O conteúdo dos autos de infração é determinante para o tipo de encaminhamento dado ao processo administrativo, devendo conter não só a descrição da conduta, mas, sobretudo, as condições da autuação, a pessoa que comete o dano, seus hábitos culturais e condições socioeconômicas, de forma a garantir a individualização da multa.

Optamos por organizar os dados por meio da elaboração de duas tabelasbase, que serviram para a confecção de múltiplas tabelas considerando eixos específicos. Esta divisão justifica-se pela necessidade de separar os processos que estavam em andamento e os que se encontravam arquivados, devido ao tratamento procedimental diferenciado. A partir de uma leitura flutuante das "tabelas-mãe", pudemos classificar o material levantado, destacando: a descrição das infrações cometidas; os principais danos; a legislação aplicada; o tempo médio de duração dos processos; os tipos penais mais freqüentes; as áreas de maior incidência; os valores das multas; os principais argumentos de defesa; os argumentos dos agentes de fiscalização; o papel e o conteúdo dos laudos técnicos; a incidência de pagamentos e inadimplementos; a atuação da procuradoria, mediante seus pareceres; os eventuais ofícios da Justiça, da Delegacia Federal, do Ministério Público, ou mesmo de terceiros interessados, como no caso de pedido feito por Deputado Federal, solicitando ao Ibama Nacional o cancelamento da infração. ${ }^{7}$

5 Deixamos, portanto, consignado nosso agradecimento a todos os funcionários que pacientemente nos atenderam sempre com dedicação e atenção.

${ }^{6}$ Diante da dificuldade de localizar processos antigos, optamos por excluir os referentes aos anos de 1992 e 1993, totalizando 8 processos não feitos, diminuindo nosso total para 140.

${ }^{7}$ Deputado Federal Jorge Wilson de Mattos - PMDB, no processo nํ0 02022.004457/01-50 


\section{RESULTADOS}

Foram analisados 125 dos 140 autos compreendidos entre 1994 e 2003, num total de $89,3 \% .^{8}$

Dentre os dispositivos da LCA, o mais referido (38 vezes) é o art. 38, seguido, com 19 aparições, do art. 48. Analisando os processos, verificamos que ambos os artigos possuem limites tênues, e quanto ao material, não conseguimos distinguir nitidez na categorização entre as condutas de destruição das florestas em formação e de impedimento de sua regeneração natural. Percebemos que o art. 48 permite tal abrangência que, por exemplo, áreas agrícolas utilizadas após processo de repouso sem autorização, sejam enquadradas por dano à vegetação em estágio de regeneração, sob pena de sofrer autuação e embargo, além das sanções penais e civis. Além disso, indica quais os critérios que determinam em que medida e quando uma conduta dificulta/impede ou destrói/danifica, já que, na medida em que se destrói, também se impede a regeneração; e a descrição que corresponde ao impedimento é utilizada para condutas que de fato danificam ou destróem a vegetação. A única distinção possível, que torna a pena do art. 38 mais severa, refere-se ao fato de a área ser ou não de preservação permanente, o que não necessariamente guia o agente na aplicação do dispositivo e de sua sanção.

O art. 41 da LCA aparece em terceiro lugar, com 15 menções, e pune a ação de provocar incêndio em mata ou floresta com reclusão de 2 a 4 anos e multa, atenuando a pena, em seu parágrafo único, no caso de crime culposo.

A não-padronização no preenchimento dos autos de infração inviabiliza uma classificação precisa dos danos e demonstra a precariedade na devida adequação às formalidades legais quando do preenchimento dos autos de infração pelos agentes, os quais, além da discricionariedade na aplicação das multas, também a utilizam na tipificação de condutas.

Desse modo, por identificar que muitas vezes o mesmo dano traz tipificações legais diferentes, optamos por classificá-los nas seguintes categorias gerais aproximativas: "Destruir Floresta", "Causar Dano Direto à UC", "Caçar", "Pescar", "Explorar Recursos Minerais", "Impedir Regeneração Natural” e "Outros”.

${ }^{8}$ Quanto aos 15 casos não analisados, nem sequer se conhece seu paradeiro, havendo apenas menções em outros registros, motivo pelo qual não se atingiu a totalidade 
Consideramos para esta classificação as argumentações trazidas nas peças de defesa, contradita, despachos e ofícios, acostadas nos autos dos processos administrativos.

TABELA 1

\begin{tabular}{|c|c|c|c|}
\hline DANO & NÚMERO & ESPECIFICAÇÃO & NÚMERO \\
\hline \multirow[t]{5}{*}{ Destruir Floresta } & \multirow{5}{*}{59} & Sem especificação ${ }^{9}$ & 34 \\
\hline & & Incêndio & 13 \\
\hline & & Corte & 5 \\
\hline & & Entrada de Boi & 2 \\
\hline & & Exploração da Floresta & 5 \\
\hline \multirow[t]{5}{*}{ Dano Direto à UC } & \multirow{5}{*}{10} & Emissário/Poluição & 1 \\
\hline & & Pesca/caça & 3 \\
\hline & & Dano à restinga & 3 \\
\hline & & Fogo & 2 \\
\hline & & Soltar bois & 1 \\
\hline \multirow[t]{3}{*}{ Caça } & \multirow{3}{*}{13} & Unidades de Conservação & 10 \\
\hline & & APP & 2 \\
\hline & & Armazenamento/exploração & 1 \\
\hline \multirow[t]{2}{*}{ Pesca } & \multirow{2}{*}{2} & Proibida & 1 \\
\hline & & Armazenamento/exploração & 1 \\
\hline \multirow[t]{3}{*}{ Exploração Mineral } & \multirow{3}{*}{11} & Areia & 7 \\
\hline & & Argila & 1 \\
\hline & & Pedras/paralelepípedo & 3 \\
\hline \multirow[t]{3}{*}{ Impedir Regeneração Natural } & \multirow{3}{*}{18} & Sem especificação & 14 \\
\hline & & Incêndio & 3 \\
\hline & & Corte/transformação & 1 \\
\hline \multirow[t]{2}{*}{ Outros/Poluição/Licença } & \multirow{2}{*}{5} & Descumprimento de $\mathrm{Al} / \mathrm{TE}$ & 2 \\
\hline & & Falta de licença ou renovação & 3 \\
\hline
\end{tabular}

Total: 125

Para efeito de comparação entre os tipos de dano e os valores das multas e a adequação destes às descrições, cruzamos os dados referentes a alguns casos selecionados, por os termos considerados como emblemáticos, seja pelo valor ou pelas argumentações trazidas.

${ }^{9}$ Refere-se aos processos em que a conduta foi autuada nos artigos 38 ou 48, sem que houvesse nenhuma outra descrição. 


\section{Casos emblemáticos}

TABELA 2

\begin{tabular}{|c|c|c|c|c|}
\hline $\begin{array}{c}\text { № Processo - autuado/ } \\
\text { local/ dano }\end{array}$ & $\begin{array}{l}\text { Valor da } \\
\text { Multa }\end{array}$ & Tamanho/complemento & Situação atual & Comentários \\
\hline 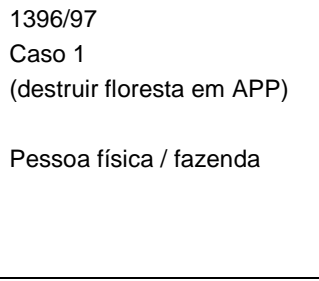 & $18.624,00$ & $\begin{array}{l}12 \text { ha/ APP - defesa: alega que o } \\
\text { caseiro não tinha ciência da APP e } \\
\text { propõe a recuperar sob orientação } \\
\text { do lbama, além de intenção de } \\
\text { criação de RPPN, apresentando } \\
\text { declaração para reduzir o valor da } \\
\text { multa. }\end{array}$ & Arquivo em 10/06/2003 & $\begin{array}{l}\text { A multa foi paga após ser reduzida } \\
\text { em } 90 \% \text { (apesar de parecer } \\
\text { contrário, visto que lei não permite } \\
\text { substituir multa por RPPN). A área } \\
\text { não se transformou em RPPN, } \\
\text { mas em pasto! Ademais, tratava- } \\
\text { se, na realidade, de pessoa } \\
\text { jurídica. }\end{array}$ \\
\hline $\begin{array}{l}7441 / 00 \\
\text { Caso } 2 \\
\text { (destruir floresta em APP) } \\
\text { Pessoa física / fazenda }\end{array}$ & $11.250,00$ & $\begin{array}{l}7,5 \text { ha } \\
\text { Não há defesa, contradita ou ofício } \\
\text { para verificação do complemento. }\end{array}$ & $\begin{array}{l}\text { Processo apensado ao } \\
7442 / 2000\end{array}$ & $\begin{array}{l}\text { Autuado analfabeto, } 2 \text { autuações e } \\
\text { processos diferentes por: } 7,5 \text { ha de } \\
\text { APP e transformar madeira de lei } \\
\text { em carvão: } 66 \mathrm{MDC}-\mathrm{R} \$ 33.000,00 \\
\text { Inscrito no CADIN. }\end{array}$ \\
\hline $\begin{array}{l}\text { 6302/02 } \\
\text { Caso } 3 \\
\text { (destruir floresta em APP) } \\
\text { Pessoa jurídica/ fazenda }\end{array}$ & $7.500,00$ & $\begin{array}{l}5 \text { ha/APP, curso d'água e topo de } \\
\text { morror (defesar alega } \\
\text { responsabilidade social, fazenda } \\
\text { detonada por queimadas, AMLD } \\
\text { busca apoio para ligar } 2 \text { reservas } \\
\text { através da propriedade. }\end{array}$ & $\begin{array}{l}\mathrm{Na} \quad \text { Dijur desde } \\
12 / 01 / 2004\end{array}$ & $\begin{array}{l}\text { Pequena empresa } \\
5,0 \text { há: } 1,2 \text { ha não é APP, trata-se } \\
\text { de mata secundária, em estágio } \\
\text { inicial e médio de regeneração e } \\
\text { área de } 3,8 \text { há em APP. } \\
\text { Indeferimento da defesa }\end{array}$ \\
\hline $\begin{array}{l}4786 / 02 \\
\text { Caso } 4 \\
\text { (destruir floresta em APP) } \\
\text { Pessoa física / } \\
\text { sítio }\end{array}$ & $6.300,00$ & $\begin{array}{l}3 \text { ha/APP - defesa nega infração, } \\
\text { apenas limpeza p/ cultivo de } \\
\text { banana, ausência de informação e } \\
\text { baixo grau de instrução; pede } \\
\text { cancelamento da multa, } \\
\text { fundamenta c/ art. } 60 \text {, parágrafo } 2^{\circ} \\
\text { do Decr. } 3.179 / 99 \text { (hipótese de } \\
\text { suspensão da multa por termo de } \\
\text { compromisso em reparar o dano); }\end{array}$ & $\begin{array}{l}\text { 04/11/2003 Notificação } \\
\text { administrativa }\end{array}$ & $\begin{array}{l}\text { Não há contradita. } \\
\text { Procuradoria lbama, em } \\
\text { 16/04/2003, opina que a multa } \\
\text { parece excessivamente alta para a } \\
\text { situação nos autos, porem não } \\
\text { houve pedido de redução do valor, } \\
\text { e para não atuar extra petita, opina } \\
\text { pela manutenção do valor. }\end{array}$ \\
\hline $\begin{array}{l}\text { 1594/01 } \\
\text { Caso } 5 \\
\text { Pessoa física/ } \\
\text { assentamento } \\
\text { (destruir floresta em APP) }\end{array}$ & 00,00 & $\begin{array}{l}1 \text { ha - segundo o termo de } \\
\text { inspeção, vegetação secundária } \\
\text { em estágio avançado de } \\
\text { regeneração, manual (defesa: } \\
\text { homem pobre, multa impagável, } \\
\text { diz que parou limpeza/ roçado e } \\
\text { contradita, quanto ao valor, alega } \\
\text { aplicação do menor permitido por } \\
\text { lei (artigo } 25 \text { do decreto } 3.179 / 99 \text { ) }\end{array}$ & $\begin{array}{l}\text { 14/03/2003 - despacho } \\
\text { da DITEC:à DIJUR para } \\
\text { averiguar legislação } \\
\text { com especificidade em } \\
\text { assentamentos rurais, } \\
\text { haja vista tratar-se de } \\
\text { Reforma Agrária }\end{array}$ & $\begin{array}{l}\text { Recurso ao presidente do lbama } \\
\text { em Brasília que determina } \\
\text { cobrança com redução de } 90 \% \text {, o } \\
\text { gerente do lbama/RJ informa } \\
\text { decisão ao autuado e solicita } \\
\text { projeto técnico para reparação do } \\
\text { dano para permitir redução da } \\
\text { multa em até } 90 \% \text { após } \\
\text { cumpridas integralmente as } \\
\text { medidas de correção total da } \\
\text { degradação. }\end{array}$ \\
\hline $\begin{array}{l}7442 / 00 \\
\text { Caso } 6 \\
\text { Pessoa física / sítio }\end{array}$ & $33.000,00$ & $\begin{array}{l}66 \text { MDC, transformar carvão em } \\
\text { madeira-de-lei. }\end{array}$ & $\begin{array}{l}20 / 08 / 2002-\text { em } \\
\text { resposta a oficio do } \\
\text { IBAMA, cartório informa } \\
\text { inexistência de } \\
\text { propriedade e DETRAN } \\
\text { a inexistência de veículo }\end{array}$ & $\begin{array}{l}\text { Não há defesa, contradita ou } \\
\text { ofício. Autuado analfabeto, } 2 \\
\text { autuações e processos diferentes } \\
\text { por desmatar } 7,5 \text { há de APP e } \\
\text { transformar carvão em madeira- } \\
\text { de-lei. } \\
\text { Inscrito no CADIN. }\end{array}$ \\
\hline $\begin{array}{l}7291 / 03 \\
\text { Caso } 7 \\
\text { (dano direto à UC) } \\
\text { Pessoa jurídica / estrada }\end{array}$ & $50.000,00$ & $\begin{array}{l}50 \text { ha, incêndio afetando à Rebio } \\
\text { (defesa alega inexistência de } \\
\text { culpa/dolo, ato de terceiros) }\end{array}$ & 19/02/2004 - à DIJUR & $\begin{array}{l}\text { Margem da BR } 101 \\
\mathrm{R} \$ 1.000,00 \text { por há destruido } \\
\text { Ainda sem parecer. }\end{array}$ \\
\hline $\begin{array}{l}7001 / 03 \\
\text { Caso } 8 \\
\text { (dano direto à UC) } \\
\text { Pessoa jurídica de direito } \\
\text { público (Prefeitura) / } \\
\text { PARNA Jurubatiba }\end{array}$ & $20.000,00$ & $\begin{array}{l}200 \mathrm{~m} 2 \text {, roçar restinga na estrada } \\
\text { de acesso ao balneário }\end{array}$ & AR juntado em 09/07/03 & $\begin{array}{l}\text { S/ defesa- Al mantido } \\
\text { Ente estatal que tem como } \\
\text { prerrogativa a proteção do } \\
\text { interesse público autuado por dano } \\
\text { ambiental }\end{array}$ \\
\hline
\end{tabular}




\begin{tabular}{|l|l|l|l|l|}
\hline $\begin{array}{l}4475 / 99 \\
\text { Caso } 9 \text { (dano direto à UC) }\end{array}$ & $1.450,00$ & Petrecho na Rebio. & $\begin{array}{l}\text { Detran informa que o } \\
\text { autuado nago s/ defesa. Noticia crime c/ art } \\
\text { veiculo cadastrado. }\end{array}$ & $\begin{array}{l}\text { Pado e 52 da Lei 9.605/98, embora } \\
\text { no Al não conste a indicação desta } \\
\text { legislação. } 2 \text { envolvidos. }\end{array}$ \\
$\begin{array}{l}\text { Pessoa física / interior de } \\
\text { UC }\end{array}$ & & & \\
\hline
\end{tabular}

\section{SELETIVIDADE A PARTIR DO DISCURSO AMBIENTAL}

O caso 6 refere-se à autuação de um dos assentados da Reforma Agrária. $\mathrm{Na}$ contradita, peça de esclarecimento do agente autuante após a defesa, "a partir de 95 nenhum grande desmatamento foi detectado, mas grande quantidade de desmatamentos entre 0,5 e 1 ha (operação formiguinha), que apesar da região ser composta por grande número de pessoas com baixo grau de instrução que são proprietários rurais, todos são sabedores da proibição do desmatamento, uma vez que é amplamente divulgada esta legislação e que se esta situação servir como excludente de punibilidade, estariam abrindo precedentes perigosos e ilegais para novas infrações com as mesmas características". Quanto ao valor, cita art. 25 do Dec. 3.179/99 (menor valor).

A alegação de que a partir de 1995 nenhum desmatamento acima de 1,0 ha foi detectado não procede, uma vez que verificamos muitos processos com extensão acima de 3 ha, como no caso 1, autuado em 17/03/1997, numa extensão de 12 ha.

Apesar de reconhecer o baixo grau de instrução da maioria da população local, o gerente da Rebio, responsável pelos autos de infração, alega ampla divulgação das proibições previstas na legislação ambiental penal. Vê-se o caráter punitivo da atuação dos agentes de fiscalização do IBAMA, que desconsideram os fatores socioeconômicos e culturais da população local para a implementação de políticas de proteção ambiental. Constitui, pois, para os agentes, a aplicação das sanções administrativas a principal forma de reprimir a ocorrência de novos danos.

Acompanhando os argumentos da contradita, a procuradoria opina pela manutenção do Al e parcelamento de multa, conforme trecho que segue:

"Não é por ser pobre, analfabeto e sem recursos para pagar a multa imposta, que ao autuado será permitido continuar cometendo crimes ambientais, a pretexto de garantir o sustento da família, violando a lei que protege a Mata Atlântica, acarretando a extinção de toda biodiversidade (...) Ficamos profundamente sensibilizados, mas somos pelo não acolhimento das razões da defesa, sugerindo a manutenção do $\mathrm{Al}$, bem como 0 parcelamento da multa aplicada". 
No caso em tela, após recurso ao presidente do Ibama em Brasília, que, diante do parecer $^{10}$ da procuradoria geral do Ibama/Brasília, determina cobrança com redução de $90 \%$, o gerente do lbama/RJ informa decisão ao autuado e solicita projeto técnico para reparação do dano para permitir redução da multa em até $90 \%$, após cumpridas integralmente as medidas de correção total da degradação.

Tal solicitação revela-se esdrúxula diante das condições econômicas do assentado, que envia nova carta, na qual agradece a diminuição da multa e envia projeto de reparação de danos, que consiste no compromisso de plantar 1 ha de árvores silvestres, conseguindo as mudas no próprio terreno, pois "não tem condição de pagar alguém para fazer", ao que, em parecer, o chefe da Ditec diz que espécimes retiradas não resistiriam à exposição direta ao sol e sugere técnico da Rebio para indicar procedimentos: "Regeneração natural é solução à vista; caso opte pelo plantio, orientação de técnico da Rebio ou da Emater/RJ para o correto plantio."

No primeiro processo da tabela 2, a multa também foi reduzida em $90 \%$, em razão de declaração do proprietário da fazenda de que iria implementar RPPN, o que não foi feito, enquanto naquele o assentado deveria comprovar a recuperação para se beneficiar da redução. Para exemplificar, segue breve relato do processo citado no caso 1.

Em 24/04/1997, a Superintendência do Ibama/RJ sugere a criação de RPPN, calcada em parecer técnico, em área remanescente de floresta da propriedade, quando, conforme legislação em vigor, poderão ter o valor do auto reduzido, bem como cancelada a autuação na Lei.

Em 17/07/1997, a divisão técnica, após vistoriar a área, afirma que, por se tratar de Área de Especial Interesse Ecológico (pois na propriedade se encontram a nascente do Rio São João e praticamente a última mancha de vegetação natural existente em toda a região - Serra do Sambê), dever-se-ia acatar a defesa, implantando RPPN, como forma de compensação, conforme art. 42 do Decreto 99.274/90. O gabinete oficiou aceitando a redução da multa, mesmo sem a juntada do documento de defesa, tendo o processo corrido em revelia. Ao final, encaminha ao SAR a redução da multa em $90 \%$, direcionando ao interessado carta

${ }^{10}$ Ementa: "adote-se o disposto no art. 60 do Dec. 3.179/99." Entende oportuno consignar a 
estabelecendo prazo de 10 dias para formalizar processo de criação de RPPN e encaminhar a Dicof.

Em 31/07/1997, é atendida a solicitação de redução da multa em $90 \%$. Decorrido 1 ano da redução, em 01/08/1999, o Mercadinho 2001 de Frios e Comestíveis Ltda., representado este ato pelo autuado, solicita reconhecimento de RPPN, conforme Decreto-Lei n. $\stackrel{1}{1.922 / 96}$, de parte de sua Fazenda do Sambê, numa área com cerca de 75 alqueres (345 ha), onde se encontra a nascente do São João e onde existe ecossistema bastante preservado, tudo em conformidade com o termo de compromisso referente ao processo 1.396/97. Entretanto, em 17/12/2001, o responsável pelo setor de RPPN informa que o proprietário não regularizou sua propriedade como RPPN. Além disso, em 22/02/2002 a gerência da Rebio informa diligência na Fazenda Sambê, com o objetivo de verificar se a área autuada foi recuperada, conforme solicitado, declarando que fora transformada em pasto.

Observamos, ainda, a partir da leitura dos documentos juntados aos autos, que a referida fazenda pertence a pessoa jurídica, representada pelo autuado que, por isso, deveria ter agravada, ao invés de reduzida, a sanção. O tratamento mais benevolente em relação ao proprietário deve-se a opção do órgão de, em sua política, priorizar o gravame de RPPNs, que oferece, ainda, algumas vantagens ao proprietário, como isenção de Imposto Territorial Rural (ITR) e o direito de propriedade garantido, ou seja, insuscetível de desapropriação para Reforma Agrária (conforme relata próprio fôlder do lbama). ${ }^{11}$

O valor mínimo previsto nos dispositivos do Decreto 3.179/99 não leva em consideração as condições e as diferenças econômicas e geográficas regionais. $\mathrm{O}$ mesmo valor de multa representa encargo diferenciado; quanto menor a renda, maior a punição, já que a multa aplicada é padrão. Além disso, a proporção do dano em 1 ha no Rio de Janeiro não é a mesma de dano idêntico praticado em mesma extensão no Estado de Goiás, por exemplo.

multa à capacidade econômica do autuado a fim de que não seja impagável.

${ }^{11}$ Segundo informação retirada do site do Ibama, existem 37 RPPNs no Estado do Rio de janeiro, que totalizam $3.437,24$ ha. Destas, 32 foram criadas a partir de 1994 . Cf. última visita a página http://www2.ibama.gov.br/unidades/rppn/lista.rtf, no dia 31 de março de 2005, que trazia a listagem atualizada das RPPNs por estado, datada em 17 de agosto de 2004. 


\section{AUSÊNCIA DE SISTEMATIZAÇÃO}

O caso 6 se relaciona com o caso 2. Os processos referentes aos dois casos estão apensados; ambos originados de autos lavrados no mesmo dia e local e em face da mesma pessoa. Novamente percebemos a falta de sistematização nos procedimentos. Este é um dos esparsos casos em que foram lavrados dois Als num único ato.

Muitas vezes, os autos são lavrados no nome do trabalhador, ante a dificuldade de encontrar o proprietário. Neste caso, é provável que o auto não tenha sido lavrado em nome do proprietário, mas sim do trabalhador que recebia ordens para efetuar os danos. As multas cominadas totalizam $R \$ 44.250,00$.

Após solicitação do lbama/RJ visando executar o autuado pelo não pagamento da multa, o cartório informa que não há propriedade, e o Detran informa que não há veículo em seu nome, o que torna a multa inexeqüível. Talvez, o Incra, se consultado, pudesse indicar o nome do proprietário da fazenda autuada.

O caso 7 da tabela 2 possui a maior multa aplicada e representa dano na maior extensão - área de 50 ha. $O$ autuado é pessoa jurídica. $O$ relatório conclui a origem, mas não identifica a causa do incêndio e informa, ainda, que o ponto da fazenda onde o incêndio se iniciou é de difícil acesso, sendo inadmissível a defesa de ter sido causado por terceiros, transeuntes, como é o caso dos incêndios iniciados próximo à BR. Em complemento, a Rebio União apresenta memorando informando que diante do resultado da perícia técnica sobre o incêndio em 03/03/2003 (PREVFOGO), somente nesta data foi possível lavrar o termo. Incêndio iniciado em 03/03/2003 e controlado apenas em 14/03/2003, extinto em 31/03/2003, e monitoramento até $05 / 05 / 2003$. Não há laudo de vistoria.

\section{Atuação do poder público}

No caso 8, o autuado é a administração municipal. Representa o único caso levantado de autuação a ente do Poder Público, o que nos intrigou, tendo em vista que o processo de ocupação do território nesta região sempre se deu de forma impactante. Como exemplo, temos a BR-101, que passa nas portas da reserva; a 
barragem de Jurtunaíba, que inundou $35 \%$ da Rebio; e as monoculturas do arroz e da cana-de-açúcar, que geraram muito desgaste ao solo do entorno.

Diante das informações contraditórias, podemos concluir que:

1) A ausência de defesa apenas torna mais célere a decisão pela manutenção dos autos, tendo em vista que a superintendência tem como praxe acatar os pareceres dos procuradores.

2) O pagamento da multa sem apresentação de defesa leva ao arquivamento do auto sem maiores detalhes com relação à participação.

3) A caça não é efetuada por assentados/acampados, conforme declaração do gerente da Rebio Poço das Antas de que o custo da munição não está dentro das possibilidades econômicas desses agentes.

Os princípios do Direito Penal devem ser utilizados pela administração no exercício do poder de polícia, tendo em vista que de fato sanciona condutas. Estas, de acordo com tais princípios, para serem passíveis de punição (seja de caráter patrimonial, como nas multas, seja de caráter pessoal) devem estar tipificadas com clareza, de forma a não deixar margem ao arbítrio do agente administrativo.

\section{Índice de pagamentos}

Buscando verificar o índice de pagamentos e inadimplementos, trabalhamos com a tabela de processos arquivados, uma vez que os processos em andamento encontram-se em fases distintas de processamento, não sendo comparáveis neste aspecto. Ademais, separamos os processos em que houve o pagamento (35) sem questionamento, ou seja, à revelia (25); e os processos em que houve defesa (10). Para os que não efetuaram o pagamento (9), subclassificamos os processos em: revelia (1), inscrição no Cadin e Dívida Ativa(1); defesa e inscrição no Cadin ou cancelamento do $\mathrm{Al}$ (1); penal ou sem valor de multa. ${ }^{12}$

\footnotetext{
${ }^{12}$ Alguns autos de infração compreendidos entre 1994 e 1998 não possuíam o preenchimento do espaço referente ao valor da multa, ou traziam a referência PENAL. Acreditamos que tal fato se deva à legislação que não previa multas para determinados crimes ambientais. Estes somente eram encaminhados à Delegacia para instaurar inquérito.
} 
O primeiro dado que nos chama a atenção é o alto índice de pagamentos, sem discussão, o que leva ao arquivamento do processo. Destes, alguns possuem despacho para que o agente da Rebio verifique o cumprimento do termo de embargo. Outros, apenas para ciência do pagamento da multa.

Cumpridas tais formalidades, o processo é arquivado, sem realização de perícia ou vistoria no local ou menção do que ocorre com o termo de embargo, ou seja, verificado ou não o cumprimento do embargo, o processo é arquivado da mesma forma, sem que se desenvolva nenhuma ação visando à reparação do dano. Depois de arquivado, não há acompanhamento.

O desembargo da atividade/área ou a liberação dos instrumentos apreendidos ocorrem mediante decisão judicial ou diante de solicitação após o pagamento da multa. Novamente aparece a seletividade da administração. Enquanto em um dos casos, após o pagamento, o trabalhador solicita liberação de instrumento de sobrevivência e tem a informação da gerência executiva de que só irá liberar o instrumento após decisão judicial - contrariando parecer da procuradoria que se remete a dispositivo expresso da LCA, em outro, constatamos a liberação imediata após o pagamento da multa. A vistoria, quando não há defesa, apenas ocorrerá se houver solicitação, pelo Ministério Público ou Delegacia Federal, para responder quesitos.

Dos 44 processos arquivados, apenas 12 autuados apresentaram defesas, sendo que somente um teve o auto de infração cancelado. $O$ cancelamento se deu por não ter o agente aguardado o prazo estabelecido no auto de notificação.

O único caso de cancelamento se fundamenta em descumprimento de formalidades técnico-processuais, o que demonstra a ineficácia das defesas e recursos, principalmente no que concerne ao mérito, no contencioso administrativo ambiental.

A opção de pagamento pode ser menos onerosa para alguns. Entre os autos quitados, 16 referem-se ao período compreendido entre 2001 e 2003, sendo que 15 não apresentaram defesa. O único que o fez foi multado no valor de $R \$ 1.000,00$ por causar dano direto ao entorno de Unidade de Conservação, com a construção de residência. 


\section{Procedimento Administrativo}

Apesar de a legislação ambiental prever a possibilidade de impugnação do valor da multa e de cancelamento dos autos de infração, visando ao cumprimento das garantias processuais de contraditório e ampla defesa, as alegações dos autuados são, via de regra, sempre insuficientes para obstar as multas. Devido aos atributos dos atos administrativos, que conferem poderes exorbitantes aos seus agentes, inclusive o poder de polícia, as sanções são aplicadas independentemente de comprovação ou avaliação do dano.

A natureza de um dano enseja responsabilidade nos âmbitos civil, penal e administrativo. Porém, enquanto na esfera civil se aplica a responsabilidade objetiva, consistente na obrigação de reparar o dano, independentemente de comprovação de culpa na ação ou omissão do autor; na esfera administrativa e penal há que se averiguar o nexo de causalidade entre a ação/omissão e o resultado alcançado, para então alcançar o grau de culpabilidade do agente, no momento da cominação da pena.

Observada a responsabilidade subjetiva, é necessário, ainda, distinguir entre o dolo eventual e a culpa consistente, para justificar um tratamento diferenciado na aplicação de penas para pessoas jurídicas, a fim de equalizar o tratamento punitivo adequado a quem se destina.

Essas e outras razões diversas, que poderiam ser esmiuçadas diante dos exemplos práticos demonstrados, permitem concluir que 0 procedimento administrativo carece de instrumentos de controle efetivo que apontem aspectos garantísticos e afinados com uma tecnologia democrática. $O$ cidadão comum encontra-se sem socorro diante do arbítrio do agente público.

Confirmamos a assertiva já feita de desconsideração das circunstâncias que limitam a imposição e a gradação de penalidades, como a gravidade do fato, os antecedentes e a situação econômica do infrator; descritos no artigo 6으 da LCA e no artigo $6^{\circ}$ do decreto 3.179/99. Da mesma forma, as situações atenuantes e agravantes no momento da aplicação das penas, como o baixo grau de instrução ou escolaridade e o arrependimento, entre os primeiros, e a reincidência, a obtenção de vantagem pecuniária, o interesse de pessoa jurídica, para o segundo tipo. 
O fornecimento dessas informações nos autos de infração é extremamente pertinente para a individualização da pena às condições e características do infrator. A Lei é genérica e abstrata, sendo o auto de infração responsável por trazer os elementos básicos que determinam o tipo de andamento dado ao procedimento administrativo.

Dentre as regras que orientam a interpretação da lei, devem ser lembrados os princípios da isonomia, da eqüidade e da racionalidade. A pena pecuniária, por si só, carrega distorções. O valor padrão, aplicado para pessoas com capacidades econômicas completamente diferentes, pune de forma mais severa aqueles que já são punidos com a falta de renda e de políticas sociais.

As vistorias técnicas são realizadas pelos analistas da Rebio, que, na maioria dos casos, apenas confirmam as alegações dos agentes de fiscalização. Não verificamos nenhum caso em que a vistoria ou perícia tenha desmentido ou minimizado as contraditas dos agentes.

Considerando os atributos do ato administrativo, temos que a presunção de legitimidade, que autoriza a imediata execução dos atos administrativos - mesmo que argüidos com defeitos ou nulidades -, transfere o ônus da prova ao administrado; o que em si já pode ser questionado, tendo em vista a dificuldade de muitos administrados que se encontram em posição "hipossuficiente" em relação ao poder público. Estes atributos fundamentam-se no princípio da supremacia do interesse público sobre o privado, o qual exige celeridade. Entretanto, podemos questionar até que ponto o interesse da administração, mediante a execução de suas políticas, de fato corresponde ao interesse público. A análise dos autos de infração traz de forma bastante clara a seletividade em que operam os agentes da fiscalização.

\section{Áreas de maior incidência de autuações}

TABELA 9

\begin{tabular}{|l|l|}
\hline \multicolumn{1}{|c|}{ ÁREAS/AGENTES } & \multicolumn{1}{c|}{ NÚMERO DE INCIDÊNCIA } \\
\hline Fazendas & 36 (23 em andamento e 13 arquivados) \\
\hline Sítios & 35 (23 em andamento e 12 arquivados) \\
\hline Rebio (Poço das Antas) & 22 (14 em andamento e 8 arquivadas) \\
\hline Assentados/Acampados & 8 (em andamento) \\
\hline Outros (estrada, lagoa, praia etc.) & 24 (7, 2, 2, respectivamente/ 13 em andamento e 11 arquivados) \\
\hline
\end{tabular}


A partir da tabela 9, podemos afirmar que o maior número de autuações se dá em relação aos fazendeiros, grandes proprietários da região, responsáveis também pelos maiores e mais graves danos verificados, seguidos pelos sitiantes. $O$ número de assentados autuados se mostrou infinitamente menor, contrariando as denúncias de que seriam os principais causadores de danos à Reserva.

Tal fato nos causou estranheza, pois não verificamos Ações Civis Públicas contra nenhuma fazenda das citadas. No entanto, uma ACP foi exatamente o que propiciou o laudo, do qual derivou o presente trabalho. Esta possuía diversos documentos acusando os trabalhadores rurais assentados de serem os maiores “impactantes a biota da Reserva Biológica de Poço das Antas".

As irrisórias multas aplicadas aos grandes proprietários também constituem um fator que pode contribuir para esse resultado. Enquanto os entes estatais se orgulham de ter na região a maior concentração de RPPNs do Estado do Rio de Janeiro, tratadas como política prioritária tanto pela Associação Mico Leão Dourado (AMLD) quanto pela gerência da Rebio Poço das Antas têm também os maiores danos autuados situados nas fazendas e sítios, tidos como principais parceiros ambientais.

\section{CONCLUSÕES ARTICULADAS}

4) A função social, incorporada no ordenamento jurídico brasileiro, impõe limite ao direito de propriedade, ao Ihe atribuir caráter coletivo, devendo ser compreendida no seu sentido quadridimensional, qual seja, a produtividade, o respeito ao meio ambiente, às relações de trabalho e ao bem-estar dos trabalhadores e da comunidade produtiva.

5) É preciso que as autoridades públicas, sobretudo o Incra e o lbama, executores diretos das políticas, estejam convencidos da necessidade de conjugação, para fortalecer os efeitos de suas ações. O Incra desconsidera os impactos ambientais e sociais, quando a propriedade aufere altos índices de lucratividade. Os proprietários destruidores do meio ambiente são beneficiados por incentivos fiscais nas políticas ambientais. Assim, a sustentabilidade da exploração agrícola é dimensão fundamental a ser considerada por ambas as políticas. 
6) As políticas voltadas para a proteção ambiental não identificam e atacam as causas dos crescentes problemas ambientais, limitando-se a buscar a compensação de danos mediante recursos limitados, levando a um círculo vicioso.

7) O controle da discricionariedade dos atos administrativos deve passar por critérios de motivação da decisão que, em analogia à exigência expressa pelo art. 93, IX, da Constituição Federal, exige a fundamentação, sob pena de nulidade.

8) Os problemas ambientais estão intrinsecamente relacionados com 0 modelo e a lógica de utilização e exploração econômica da propriedade. A transformação deste, portanto, faz-se necessária para que o homem se veja como parte da natureza e perceba que a vida equilibrada e harmoniosa depende da relação que estabelece com o mundo.

\section{BIBLIOGRAFIA}

IBAMA. RPPN. http://www2.ibama.gov.br/unidades/rppn/lista.rtf, acesso em 31/mar/2005

JONES, Alberto da Silva. Reforma agrária e direito de propriedade. In: MOLINA, Mônica Castagna; SOUZA JÙNIOR, José Geraldo de; TOURINHO NETO, Fernando da Costa (orgs). Introdução crítica ao direito agrário. Brasília: UnB, 2002 (Série "O direito achado na rua", vol. 3)

MACHADO, Paulo Affonso Leme. Direito ambiental brasileiro. 10 edição. São Paulo: Malheiros Editores, 2002, p. 406..

MADEIRA FILHO, Wilson et al. Laudo multidisciplinar e termo de cooperação técnica para a convivência harmoniosa de assentamentos rurais no entorno da Reserva Biológica de Poço das Antas. Niterói: UFF, 2002. (CD Room). Também disponível em www.crea-rj.org.br_, acesso em 20/abr/2005

MARES, Carlos Frederico. A função social da terra. Porto Alegre: Sergio Antonio Fabris Editor, 2003, p. 50.

ULTRAMARI, C. Das falácias naturalistas. In: http://www.unilivre.org.br/centro/textos/forum/falacias. Acesso em 20 de abril de 2004. 